\title{
Effect of Tooth Brushing on Wear of Microhybrid Composites In vitro experiment
}

\author{
CSABA DUDAS ${ }^{1}$, MELINDA SZEKELY1*, MARIA HENRIETTA GABOR ${ }^{2}$, LASZLO JAKAB FARKAS ${ }^{3}$, KINGA DORNER $^{4}$, \\ VANDA ROXANA NIMIGEAN ${ }^{5}$, VICTOR NIMIGEAN ${ }^{5}$, CRISTINA MOLNAR-VARLAM ${ }^{1}$, BERNADETTE KEREKES-MATHE ${ }^{1}$ \\ ${ }^{1}$ University of Medicine, Pharmacy, Science and Technology, Faculty of Dental Medicine, Department of Morphology of Teeth \\ and Dental Arches; Technology of Dental Prosthesis and Dental Materials, 38 Gh.Marinescu Str., 540139, Targu Mures, Romania \\ 2 University of Medicine, Pharmacy, Science and Technology of Targu Mures, Faculty of Dental Medicine, 38 Gh.Marinescu Str., \\ 540139, Targu Mures, Romania \\ ${ }^{3}$ Sapientia Hungarian University of Transylvania, Faculty, Department of Electrical Engineering, 1 Decembrie 1918 Str., 540485 , \\ Corunca/Targu Mures, Romania \\ ${ }^{4}$ University of Medicine, Pharmacy, Science and Technology, Faculty of Dental Medicine, Department of Removable Prosthetic \\ Dentistry, 38 Gh.Marinescu Str., 540139, Targu Mures, Romania \\ ${ }^{5}$ Carol Davila University of Medicine and Pharmacy, Faculty of Dental Medicine, Oral Rehabilitation Department, 17-23 Calea \\ Plevnei Str., 010231, Bucharest, Romania \\ ${ }^{6}$ Carol Davila University of Medicine and Pharmacy, Faculty of Dental Medicine, Anatomy Department, 17-23 Calea Plevnei, \\ 010231, Bucharest, Romania
}

\begin{abstract}
Changes in the surface roughness of dental restorative materials after tooth brushing are inevitable. The abrasion is known to increase the possibility of dental plaque accumulation which is responsible for several pathologies of the oral cavity. The aim of this in vitro study was to evaluate the changes of surface roughness of microhybrid composite materials produced by different toothbrushes with and without toothpaste. Fortyeight specimens of two composite materials (Charisma and Super-Cor) were prepared using a silicone template according to the manufacturer's instructions. Each sample was brushed for eight hours. Each group of specimens was divided in two subgroups: half of the samples were brushed using only distilled water and the other half with a mixture of distilled water and toothpaste (Colgate Total; ratio 1:1). The average roughness value $(R a)$ of surfaces were measured with profilometer three times: the initial measurement was performed before starting the toothbrush simulation, the second was after 4 hours and the third was after 8 hours of brushing. Three different bristle stiffness toothbrush heads were used (medium sensitive, medium and soft). After collecting all numerical data one-way ANOVA and Friedman tests were performed for statistical analysis. All examined microhybrid composites exhibited changes in surface roughness after the toothbrush simulation. The simulation of toothbrushing without toothpaste, only with water as cleaning substrate, showed at every measurement the lowest values of roughness in all three toothbrush heads. Significantly increase of mean Ra values were observed in both tested composite samples when medium and soft toothbrushes with toothpaste were used. The surface roughness changes of tested microhybrid composites depend on the brushing procedure. The toothpaste has a much greater effect on the abrasion than the type of toothbrush.
\end{abstract}

Keywords: microhybrid composite, surface roughness, in vitro, toothbrush, toothpaste

Microhybrid resin composites are the results of trend in dental restorative material development which shows a reduction in size of filler particles. While the average particle size of first, so-called macrofill composites were 10-50 $\mu \mathrm{m}$, with further refinements sub-micron particles appeared in the composition, estabilishing the category of microhybrid composites [1]. The fillers and resins together determine the properties of the composite such as aesthetics (texture, translucency and colour), hardness, polymerization shrinkage and polymerization stress [2,3]. The development of new composite materials containing nano-size particles could not reduce the popularity of microhybrid composites among the dentists. This is the consequence of their favourable properties such like-as universal application in anterior and posterior area, appropriate strength and polishability, and last but not least a relatively affordable price [1].

Changes occurring at the surface of the dental restorative materials are determined by their own chemical properties and external factors which are mainly patient-related variables: diet, recurrent acidic environment, and possible bad behaviours of clenching and grinding presents large variability among individuals. Oral hygiene due to the different toothbrushing methods using a wide range of toothbrushes and toothpastes may cause tooth wear and also the wear of aesthetic dental restorations [4-6]. The tilt of mandibular molars in the Curve of Spee can cause also an increased wear of composite restorations [ 7]. When the degree of polymerization of light-cured composite materials is inadequate due to failure of the operator or light curing unit, respectively, there may occur a reduced hardness and an increased wear rate [8-10]. The lack of succes of composite restorations is often the consequence of changes taking place between the polymer matrix and the silanized filler particles of the material, as well as at the interface layer [11].

One of the most important requirement for composites, after the reduction of polymerization shrinkage, is the wear resistance because surface roughness is a major source of plaque accumulation and discoloration [12, 13]. The 
effect of toothbrush on surface roughness of composites was shown by many studies, however the issue is not clarified yet [14]. There are publications available in the scientific literature which confirm that hard or medium toothbrushes produce more pronounced abrasion than soft brushes [15] and there are also articles supporting the opposite statement [16, 17]. The latter theory is supported by the fact that soft brushes own smaller diameter filaments and denser tufts, creating a larger contact surface which retains more toothpaste [18]. The composition of toothpaste also plays a role in surface roughness. The addition of silicone oil in toothpaste can reduce the abrasion and make the surface smoother [19].

The aim of the study was to evaluate in vitro the surface roughness changes of two microhybrid resin composites induced by the simulation of different toothbrushing techniques - with or without toothpaste - under controlled conditions. The null hypotheses tested were that the technique and method of toothbrushing have no effects on surface roughness of microhybrid composites (1) and there is no relationship between the bristles properties of brushes and wear (2).

\section{Experimental part}

Material and methods

In the present study 48 specimens of - discs with $5 \mathrm{~mm}$ diameter and 3mm thickness - microhydrid composite samples were used: 24 samples of Charisma Classic (Heraeus Kulzer, Germany) and 24 samples of Super-Cor (Spofa Dental, Czech Republic) (Table 1). In order to prepare the specimens a silicone mold was used. All the specimens were prepared following the manufacturer's instructions. The samples were divided in 6 subgroups according to the brushing methods: with use of toothpaste or without toothpaste, medium (2 types) or soft type brushes (Dontodent, dm, Germany). The bristle size of medium toothbrushes was $0,15 \mathrm{~mm}$ and of soft toothbrush $0.14 \mathrm{~mm}$, respectively.

For brushing simulation, a custom-made device was used containing two electric toothbrushes, which provided a $2 \mathrm{~N}$ force transmission at $8800 \mathrm{rpm}$. Samples were placed under the head of a brush in a damp medium similar to the oral cavity and an $8 \mathrm{~h}$ simulation was performed. In total, 384 hours of simulation were performed.
The measurement of surface roughness was performed on three occasions: before brushing simulation, after 4 hours and after $8 \mathrm{~h}$ of brushing simulation. For measuring purposes the MarSurf Xr1 - SD 26 (Mahr, Germany) surfometer was used. The tip of the device linearly measured each sample on the two opposite diagonals. Thus, four values were obtained for each specimen surface on each occasion. The results showed the magnitude of the material deficiencies on the composite specimen surface in im order. The rugosimeter determined the Roughness Average ( $\mathrm{Ra}$ ) value which is a qualitative numeric information.

The visualisation of topographic shape and physical properties of the sample surfaces was made with SEM (J EOL 5200). This enabled to observe the specimens with $100 x$ and $500 x$ resolution at 0and $45^{\circ}$. Thus, surface changes of microhybrid composites became visible from the initial, pre-simulated phase to the end of toothbrushing simulation.

The numeric data obtained with the rugosimeter were collected in Microsoft Excel, the statistic analysis was made with GraphPad Prism 6. If the paired samples in data showed normal distribution Repeated measures one-way ANOVA, in case of non-Gaussianity Friedman tests were made. Statistical significance level was set at $p<0.05$.

\section{Results and discussions}

In case of Charisma microhybrid composite material (Table 2) the brushing method without toothpaste slurry, using only water, did not cause any wear as the measurements show. Significant differences between measurements could be observed in case of simulation with medium head brush and tooth paste (Medium and Colgate Total) between the first and the third measurements $(p<0.001)$, respectively between the second and third $(p<0.01)$. The increase in wear between the first two measurements was not statistically significant $(p>0.05)$.

In case of the soft brush used with toothpaste (Soft and Colgate Total), the differences between the first and the second measurements $(p<0.01)$, respectively between the first and the third were statistically significant $(p<0.05)$, showing increased wear. The difference of surface roughness values between the last two measurements was not statistically significant ( $p>0.05)$.

Table 1

DESCRIPTION OF MATERIALS USED IN THE STUDY

\begin{tabular}{|l|l|l|l|l|l|}
\hline Material & Type & Batch & Manufacturer & Filler volume & Particle size \\
\hline $\begin{array}{l}\text { Charisma } \\
\text { Classic }\end{array}$ & Microhybrid & $010719 \mathrm{~A}$ & $\begin{array}{l}\text { Kulzer GmbH, Hanau, } \\
\text { Germany }\end{array}$ & $61 \%$ by volume & $0.7 \mu \mathrm{m}$ \\
\hline Super-Cor & Microhybrid & 5758616 & $\begin{array}{l}\text { Spofa Dental A.S., Markova, } \\
\text { Czech Republic }\end{array}$ & $59 \%$ by volume & avreage $0.6 \mu \mathrm{m}$ \\
\hline
\end{tabular}

Table 2

MEAN VALUES OF Ra $(\mu \mathrm{m})$ BEFORE $\left(1^{\text {st }}\right)$, after $4 \mathrm{~h}\left(2^{\text {nd }}\right)$ AND AFTER $8 \mathrm{~h}\left(3^{\text {rd }}\right)$ OF BRUSHING SIMULATION WITH OR WITHOUT TOOTHPASTE IN CHARISMA CLASSIC MICROHYBRID COMPOSITE SAMPLES $(n=24)$

\begin{tabular}{|c|c|c|c|c|}
\hline $\begin{array}{l}\text { CHARISMA CLASSIC } \\
\text { Toothbrush } \pm \text { toothpaste }\end{array}$ & $\begin{array}{l}1^{\text {st }} \quad \text { measurement } \\
\text { mean }( \pm S D) \mu \mathrm{m}\end{array}$ & $\begin{array}{l}2^{\text {ad }} \text { measurement mean } \\
( \pm S D) \mu \mathrm{m}\end{array}$ & $\begin{array}{l}3^{\text {rd measurement mean }} \\
( \pm \mathrm{SD}) \mu \mathrm{m}\end{array}$ & $p$ \\
\hline Sensitiv Activ + Water & $0.597( \pm 0.347)$ & $0.443( \pm 0.208)$ & $0.599( \pm 0.356)$ & 0.085 \\
\hline Medium + Water & $0.426( \pm 0.206)$ & $0.371( \pm 0.116)$ & $0.542( \pm 0.273)$ & 0.096 \\
\hline Soft + Water & $0.594( \pm 0.532)$ & $0.419( \pm 0.235)$ & $0.508( \pm 0.462)$ & 0.580 \\
\hline $\begin{array}{l}\text { Sensitiv Activ + Colgate } \\
\text { Total }\end{array}$ & $0.718( \pm 0.385)$ & $0.716( \pm 0.454)$ & $0.669( \pm 0.312)$ & 0.841 \\
\hline Medium + Colgate Total & $0.815( \pm 0.815)$ & $1.215( \pm 0.654)$ & $2.946( \pm 1.322)$ & 0.0006 \\
\hline Soft + Colgate Total & $0.376( \pm 0.256)$ & $1.29( \pm 1.09)$ & $1.107( \pm 0.606)$ & 0.0075 \\
\hline
\end{tabular}


Table 3

VALUES OF Ra $(\mu \mathrm{m})$ BEFORE $\left(1^{\text {st }}\right)$, after $4 \mathrm{~h}\left(2^{\text {nd }}\right)$ AND AFTER $8 \mathrm{~h}\left(3^{\text {rd }}\right)$ OF BRUSHING SIMULATION WITH OR WITHOUT TOOTHPASTE IN SUPER-COR MICROHYBRID COMPOSITE SAMPLES $(n=24)$

\begin{tabular}{|c|c|c|c|c|}
\hline $\begin{array}{l}\text { SUPER-COR } \\
\text { Toothbrush } \pm \text { toothpaste }\end{array}$ & $\begin{array}{l}1^{\text {st }} \quad \text { measurement } \\
\text { mean }( \pm \mathrm{SD}) \mu \mathrm{m}\end{array}$ & $\begin{array}{l}2^{\text {nd }} \text { measurement mean } \\
( \pm S D) \mu \mathrm{m}\end{array}$ & $\begin{array}{l}3^{\text {rad }} \text { measurement mean } \\
( \pm S D) \mu \mathrm{m}\end{array}$ & $p$ \\
\hline Sensitiv Activ + Water & $0.611( \pm 0.149)$ & $0.923( \pm 0.461)$ & $0.86( \pm 0.55)$ & 0.171 \\
\hline Medium + Water & $0.418( \pm 0.122)$ & $0.36( \pm 0.09)$ & $0.528( \pm 0.296)$ & 0.287 \\
\hline Soft + Water & $0.27( \pm 0.116)$ & $0.27( \pm 0.121)$ & $0.319( \pm 0.176)$ & 0.486 \\
\hline $\begin{array}{l}\text { Sensitiv Activ + Colgate } \\
\text { Total }\end{array}$ & $0.551( \pm 0.288)$ & $0.957( \pm 0.941)$ & $0.682( \pm 0.369)$ & 0.146 \\
\hline Medium + Colgate Total & $0.443( \pm 0.195)$ & $1.041( \pm 1.052)$ & $1.321( \pm 0.433)$ & 0.022 \\
\hline Soft + Colgate Total & $0.673( \pm 0.09)$ & $1.368( \pm 0.114)$ & $1.323( \pm 0.119)$ & 0.03 \\
\hline
\end{tabular}

Regarding the Super-Cor dental restoration material (Table 3) no significant increase of surface roughness was measured after the use of toothbrush without toothpaste. The Sensitiv Activ toothbrush with toothpaste slurry caused a slight, statistically significant decrease of Ra, according to the measurements after 8 hours of brushing simulation. Significant increases of Ra values were found after the use of medium and soft tooth brushes with tooth paste (Medium and Colgate Total; Soft and Colgate Total).

To test the hypothesis that various techniques and methods of toothbrushing have no effects on surface roughness of microhybrid resin composites, three types of toothbrushes (sensitive activ, medium, soft) were used with and without toothpaste. Colgate Total was the toothpaste selected for the study because its wide range usage. This toothpaste contains hydrated silica and an abrasive component.

The present study revealed that there is a relationship between the selected method of toothbrushing and the resulted surface roughness of microhybrid composite. The deterioration of surfaces are not uniform, but there are some trends which are the same for both tested restorative materials: the surface roughness became higher statistically significant when medium and soft toothbrushes were used with toothpaste (Fig. 1). No other procedure generated higher Ra values than $1 \mu \mathrm{m}$. A possible explanation might be that during the brushing simulation with toothpaste slurry the larger filler particles secede from the surface of the composite sample, which is also confirmed by the results of other studies [20,21].

The simulation of brushing without toothpaste, in case of all three heads with different bristle properties, showed the lowest values of roughness which remained relatively stable at each measurement and did not cause statistically significant changes (Fig. 2 and 3). This finding confirm the results of other studies where the influence of the toothbrush in water substrate on abrasivity was not considerable, but under the influence of toothpaste the softer toothbrush had similar abrasion like the harder one [16, 21].
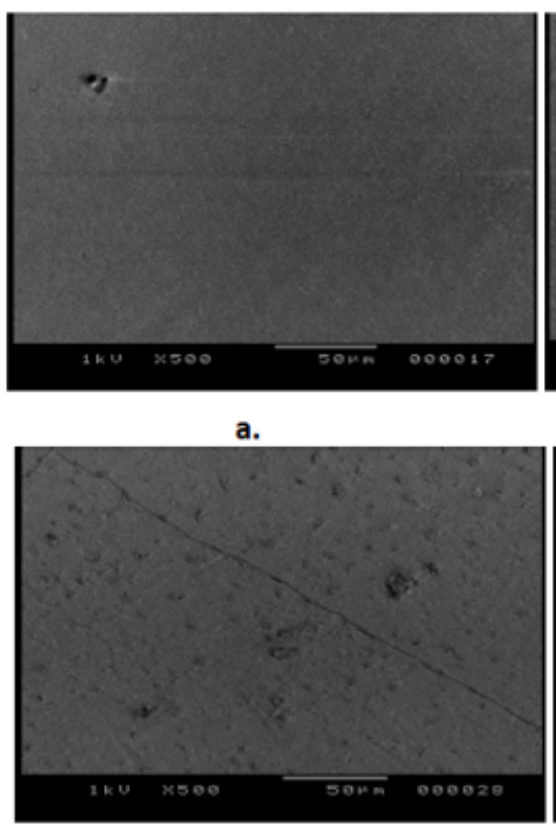

a.

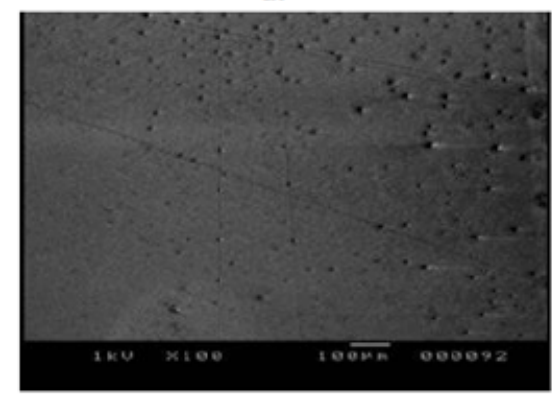

b.

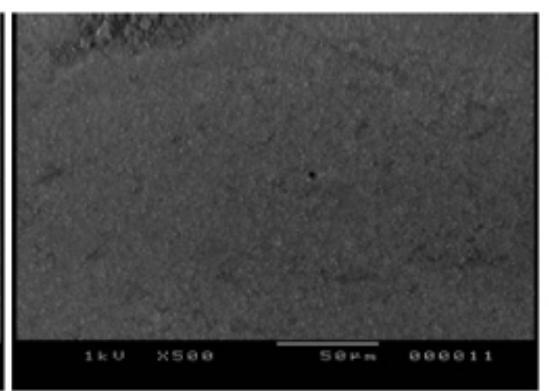

b.

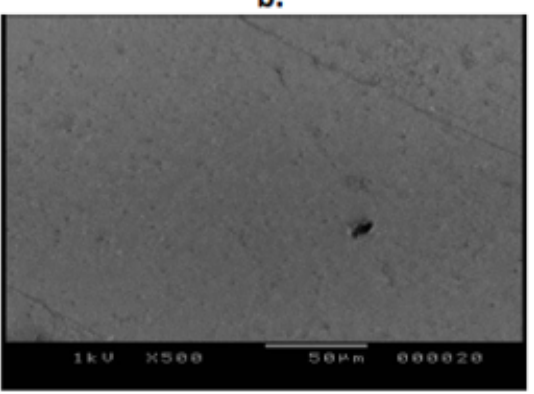

b.

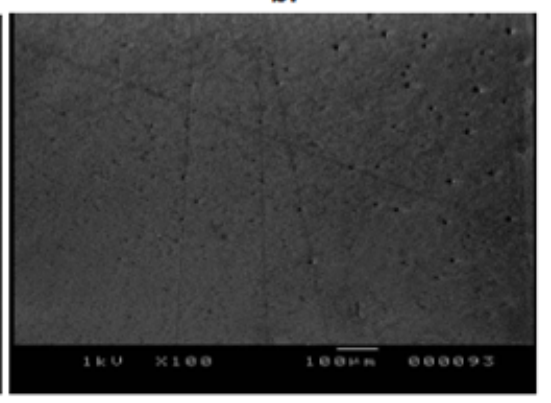

Fig. 1. SEM images of the Super-Cor Super-Cor microhybrid composite samples $45^{\circ}, \times 500$ surfaces' before (a) and after $8 \mathrm{~h} \mathrm{(b)}$ tooth brushing simulation with medium toothbrush and toothpaste

Fig. 2. SEM images of the Charisma Classic microhybrid composite samples surfaces' before (a) and after $8 \mathrm{~h}(\mathrm{~b})$ tooth brushing

Charisma $45^{\circ}, \times 500$ simulation with medium toothbrush and without toothpaste (water)
Super-Cor

$45^{\circ}, \times 100$
Fig. 3. SEM images of the SuperCor microhybrid composite samples surfaces' after $4 \mathrm{~h}$ (a) and after $8 \mathrm{~h}$ (b) tooth brushing simulation with medium toothbrush and without toothpaste 
An other finding of the study was that despite the fact that microhybrid composite samples were produced under laboratory conditions by a single operator respecting manufacturer's instructions, the resulted specimens at initial profilometer measurement did not show uniform Ra values of surface roughness. All measurements made before and after simulation exceeded $0.2 \mu \mathrm{m}$ which is a theoretical roughness threshold of intraoral hard surfaces. According to Bollen et al. above this value, the increase of plaque accumulation, risk of caries and periodontal inflammation, is more prominent because the conditions for bacterial adhesion and colonization are assured [22]. Other studies have not confirmed the role of this value in plaque accumulation and reported this phenomenon when surface roughness was in the range of 0.7-1.44 $\mu \mathrm{m}[23$, 24].

In other studies, the Ra of restorative materials during toothbrush simulation decreased, indicating a polishing effect [ 21,25$]$. The smoother surface can appear both as a result of toothpaste usage or absence of it. A possible explanation might be that through properties of micro filler content no or very few filler particles have emerged. In present study the presence of this phenomenon was not remarkable. Although when using the toothpaste in case of both microhybrid materials there was a slight decrease of Ra between the second and third measurements, it was negligible overall and did not change the fact that between the first and final measurements the surface roughness increased significantly. In the SEM images itis clearly visible the decreases in Ra values, even if they are statistically not significant, can create smoother surfaces (Fig. 2 and 3).

Under experimental conditions the resin-based composites presented surface changes in several studies. The surface degradation showed the wear resistance of these dental restorative materials [26, 27]. How ever, in vitro studies can provide valuable information, they do not entirely reflect the clinical performance of composite restorations $[6,28,29]$.

In vivo studies can provide the most relevant informations regarding the behaviour of microhybrid composite restorations in oral cavity. An in vivo study showed after 60 months of observation that there was no significant difference between the mean vertical wear of microhybrid (Z100; 77 $\pm 25 \mu \mathrm{m})$ and nanofilled (Filtek Supreme; $84 \pm 21 \mu \mathrm{m}$ ) composite in Class I and II restorations. The wear rate was the highest in the first six months after which the growth trend was maintained [7]. In clinical studies where the modified United States Public Health Service (USPHS) criteria were used, after the same period of time, $96.6 \%$ of microhybrid (Filtek Z250) and 95\% of nanofilled (Filtek Supreme XT) composite restorations remained smooth [30], while in an other study the roughness of microhybrid (Filtek Z250) restorations were the second best before nanofilled (Filtek Z350) and after nanohybrid (Esthet- $X$ ), respectively [31].

In Romanian Dental Medicine there are also other recent in vivo and in vitro experimental study, performed especially in the fields of implantology and endodontics [32-35].

Based on the results of this study, the tested hypotheses were rejected. The alternative hypotheses which states that the technique and toothbrushing method have effects on the surface roughness of microhybrid resin composites (1) and there is a relationship between the bristle properties of toothbrushes and wear (2) seem to be proven. Although the obtained results are in accordance with the findings of similar articles, further studies with a higher number and variety of specimens are needed in this domain.

\section{Conclusions}

According to the results of the present study, with all restrictions of the in vitro study design, the type of the toothpaste has a greater impact on surface roughness of microhybrid composites than the bristle properties of toothbrushes. The level of wear in water substrate is not remarkable, but if toothpaste is added substantial wear might result even when using a soft brush. The initial Ra level of the studied restorative materials presented a relatively increased value of Ra which is a risk factor for plaque accumulation. Choosing a restorative material with a low surface roughness value and higher wear resistance is the mostimportant in the cervical area of the teeth where plaque accumulation affects gingival health.

\section{Refrences}

1.FERRACANEJ L., Resin composite - State of the art, Dent. Mater., 27, 2011, pp. 29-38.

2.PODARIU, A.C., JUMANCA, D., GALUSCAN, A., POPOVICI, R. A., PODARIU, A. S., NITIPIR, C., CHISCOP, I., BARLEAN, L. M., Evaluation of Impact of Technological Factors on Dental Composites, Mat. Plast., 52, no. 4, 2015, p. 605-607.

3.VOICU, G., CONSTANTIN, G.A., SARACIN, A., Simulation of Mechanical Behaviour in Milling and Polishing of Dental Polymeric (resin) Composites, Mat. Plast, 54, no. 2, 2017, p. 308-314.

4.TOFAN, N., PANCU, G., TOPOLICEANU, C., GEORGESCU, A., STOLERIU, S., ANDRIAN, S., Study Regarding the Erosive Potential of Water from Swimming Pools on Dental Hard Tissues, Rev. Chim. (Bucharest), 66, no. 12, 2015, p. 1974-1977.

5.MONTEIRO B., SPOHR A.M., Surface Roughness of Composite Resins after Simulated Toothbrushing with Different Dentifrices, J Int Oral Health, 7, no. 7, 2015, pp. 1-5.

6.BORS, A., ANTONIAC, I., COTRUT, C., ANTONIAC, A., SZEKELY, M., Surface analysis of contemporary aesthetic dental filling materials after storage in erosive solutions, Mat. Plast, 53, no. 4, 2016, p. 607611.

7.PALANIAPPAN S., BHARADWAJ D., MATTAR D.L., PEUMANS M., VAN MEERBEEK B., LAMBRECHTS P., Nanofilled and microhybrid composite restorations: Five-year clinical wear performances, Dent Mater, 7, 2011, pp. 692-700.

8.ST-GEORGE A., SWIFT E., THOMPSON J ., HEYMANN H.O., Curing Light Intensity Effects on Wear Resistance of Two Resin Composites, Oper Dent, 27, 2002, pp. 410-417.

9.PRICE R.B., DEFRAND T., LONEY R.W., Effect of light source and specimen thickness on the surface hardness of resin composite, Am J Dent, 15, no. 1, 2002, pp. 47-53.

10.DIONYSOPOULOSD., PAPADOPOULOSC., KOLINIOTOU-KOUMPIA $\mathrm{E}$., Effect of temperature, curing time, and filler composition on surface microhardness of composite resins, J Conserv Dent, 18, no. 2, 2015, pp. 114-118.

11.STAN, A.S., VADUVA, A., NEGRUTIU, M.L., SINESCU, C., SZUHANEK, C., ROGOBETE, A., MUNTEAN, D., TALPOS, S., DUMAV, F, IDORASI, L., HAJAJ , T., ROMINU, M., Evaluation of dental composite resin interface and adhesion using laser scanning confocal microscopy, Mat. Plast, 55, no. 4, 2018, pp. 541-544.

12.MEI L., BUSSCHERH J., VAN DER MEI H.C., REN Y., Influence of surface roughness on streptococcal adhesion forces to composite resins, Dent Mater, 27, no. 8, 2011, pp. 770-778.

13.LU H., ROEDER L.B., LEI L., POWERS J.M., Effect of surface roughness on stain resistance of dental resin composites, J Esthet Restor Dent, 17, no. 2, 2005, pp. 102-108.

14.MUCENIC S., BERESESCU G., BORS A., CAMARASAN A., MOLNARVARLAM C., KEREKES-MATHE B., SZEKELY M., Clinical Study Regarding the Association Between Some Etiological Factors and Tooth Wear, Acta Medica Marisiensis, 57, no. 5, 2011, pp. 494-497.

15.ZAIRANI O., IRAWAN B., DAMIYANTI M., The effect of toothbrush bristle stiffness on nanohybrid surface roughness, J Phys Conf Ser, 884, no. Conference 1, 2017. 
16.TELLEFSEN G., LILJEBORG A., JOHANNSEN A., JOHANNSEN G., The role of the toothbrush in the abrasion process, Int J Dent Hyg, $\mathbf{9}$, no. 4, 2011, pp. 284-290.

17.J OSHI C.P., PATIL A.G., KARDE P.A., MAHALE S.A., DANI N.H., Comparative evaluation of cemental abrasion caused by soft and medium bristle hardness toothbrushes at three predetermined toothbrushing forces: An in vitro study, J Indian Soc Periodontol, 21, no. 1, 2017, pp. 10-15.

18.DYER D., ADDY M., NEWCOMBE R.B., Studies in vitro of abrasion by different manual toothbrush heads and a standard toothpaste, J Clin Peridontol, 27, 2000, pp. 99-103.

19.J OHANNSEN G., TELLEFSEN G., JOHANNSEN A., LILJ EBORG A., The importance of measuring toothpaste abrasivity in both a quantitative and qualitative way, Acta Odontol Scand, 71, 2013, pp. 508-517.

20.VAN DIJKEN J.W.V., STADIGH J., MEURMAN J.H., Appearance of finished and unfinished composite surfaces after toothbrushing $A$ scanning electron microscopy study, Acta Odontol Scand, 41, no. 6, 1983, pp. 377-383.

21.TELLEFSEN G., LIJEBORG A., JOHANNSEN G., How Do Dental Materials React On Tooth brushing/ ?, Dentistry, 5, no. 11, 2015. 22.BOLLEN C.M.L., LAMBRECHTS P., QUIRYNEN M., Comparison of surface roughness of oral hard materials to the threshold surface roughness for bacterial plaque retention: A review of the literature, Dent Mater, 13, no. 4, 1997, pp. 258-269.

23.WEITMAN T.R., EAMES W.B., Plaque accumulation on composite surfaces after various finishing procedures, J Am Dent Assoc, 91 1975, pp. 101-106.

24.SHINTANI H., SATOU J ., SATOU N., HAYASHIHARA H.,INOUE T., Effects of various finishing methods on staining and accumulation of Streptococcus mutans HS-6 on composite, Dent Mater, 1, 1985, pp. 68.

25.DUDAS C., FORGO Z, KEREKES-MATHE B., Surface Roughness Changes of Different Restoration Materials after Tooth Brushing Simulation Using Different Toothpastes, J Interdiscip Med, 2, no. 1, 2017, pp. 21-24.

26.BORS A., MOLNAR-VARLAM C., SZEKELY M., The behaviour of composites, glass ionomers and compomers in erosive conditions in vitro study. Acta Medica Marisiensis, 60, no. 5, 2014, pp. 200-203.
27.BORS A., MOLNAR-VARLAM C., BIRTA O., SZEKELY M., Erosive wear resistance of direct restorative materials - an in vitro study. International J ournal of Medical Dentistry, 18, no. 4, 2014, pp. 278-285. 28.SZEKELY M., FULOP K., BOCSKAY S., Studii in vitro la microscopul electronic cu baleiaj privind inchiderea marginala a inlayurilor compozite. Revista Nationala de Stomatologie, 2, no. 2, 1999, pp. 4549.

29.SZEKELY M., FULOP K., Studii in vitro privind etanseitatea inchiderii marginale a obturatiilor compozite. Medicina Stomatologica, 3, no. 1, 1999, pp. 39-44.

30.TUNCER S., DEMIRCI M., OZTAS E., TEKCE N., UYSAL O., Microhybrid versus nanofill composite in combination with a three step etch and rinse adhesive in occlusal cavities: five year results, Restor Dent Endod, 42, no. 4, 2017, p. 253.

31.DE ANDRADEA K.M., DUARTER M., MEDEIROS E SILVA F.D.S.C., BATISTA A.U.D., LIMA K.C., MONTEIROG Q.M, MONTESM A.J.R, Resin Composite Class I Restorations: A 54-month Randomized Clinical Trial, Oper Dent, 39, no. 6, 2014, pp. 588-594.

32. TUCULINA M.J., RAESCU M., DASCALU I.T., POPESCU M., ANDREESCU C.F., DAGUCI C., CUMPATA C.N., NIMIGEAN V.R., BANITA I.M., Indirect pulp capping in young patients: immunohistological study of pulp-dentin complex. Rom J Morphol Embryol, 54, no. 4, 2013, pp. 1081-1086.

33.POLL A., NIMIGEAN V.R., BADITA D., BALACEANU R.A., CISMAS S.C., PERLEA P., MORARU S.A., NIMIGEAN V., In vivo experimental model for the evaluation of dental implant integration, Rom Biotechnol Lett, 23, no. 2, 2018, pp. 13505-13510.

34.POLL A., MINCULESCU C.A., NIMIGEAN V.R., BADITA D., BALACEANU R.A., PAUN D.L., MORARU S.A., NIMIGEAN V., Experimental model for the study of autogenous mandibular bone grafts integration, Rom Biotechnol Lett, 23, no. 3, 2018, pp. 13681-13689.

35. NIMIGEAN, V., POLL, A., NIMIGEAN, V..R., MORARU, S.A., BADITA, D.G., PAUN, D.L., The Routine and Specialised Staining for the Histologic Evaluation of Autogenous Mandibular Bone Grafts. An experimental study. Rev Chim (Bucharest), 69, no. 5, 2018, pp. 11061109.

Manuscript received: 26.06 .2019 